\title{
Evaluation of the effectiveness of natural stone surface treatment from Ukraine by mechanical and chemical methods
}

The Mining-Geology-Petroleum Engineering Bulletin UDC: $622.027: 679.8 .02$

DOI: $10.17794 / \mathrm{rgn} .2018 .4 .2$

Preliminary communication

\author{
Valentyn Korobiichuk'; Volodymyr Shamrai ${ }^{2}$; Volodymyr Levytskyi ${ }^{3}$; \\ Ruslan Sobolevskyi ${ }^{4}$; Oleksandr Sydorov ${ }^{5}$ \\ Faculty of Mining and Ecology, Zhytomyr State Technological University, Chudnivska 103, 10005 Zhytomyr, Ukraine \\ ${ }^{1}$ Associate Professor, ${ }^{2}$ Associate Professor, ${ }^{3}$ Associate Professor, ${ }^{4}$ Associate Professor, ${ }^{5}$ PhD student
}

\begin{abstract}
Studies have been conducted with the aim of studying ways to improve the decorative properties of natural stone products. That will allow to make a finished product run of natural stone with a homogeneous tint. For this purpose, the indicators of lustre, lightness and saturation of natural surfaces of facing stone worked by mechanical and chemical methods are described. The influence of chemical treatment on the decorative indicators of various kinds of natural facing stone depending on its mineralogical composition is determined.
\end{abstract}

Keywords:

Stone lightness, stone saturation, chemical stone working, stone lustre, digital image processing

\section{Introduction}

The characteristic feature of the natural facing stone is its decorative effect, which in combination with the performance characteristics is a property that determines its value. The appearance of the stone depends not only on its initial appearance, but also on other factors. First and foremost, the technology of working natural facing stone affects the quality of the stone, namely it emphasizes the structure and pattern of natural stone, saturates its color, whereas, the working technology provides a certain texture of facial surfaces of natural stone. In addition to the main mechanical processing methods of stone surface, chemical ones are also used.

Chemical impregnating agents are used to improve the quality of the facial surface during the finishing work of stone - polishing. The influence of chemical impregnation on the decorative properties of natural stone from Ukrainian deposits is underexplored, and as a consequence, their impact on the indicators of lustre, saturation and lightness of various types of natural stone should be investigated. Therefore, the evaluation of the efficiency of chemical treatment on different types of natural facing stone is a current scientific and practical task.

Scientific progress does not stay static. Its prerequisites are primarily associated with the increasing production requirements of consumers. So, in the stone industry, there are new methods of processing natural fac-

Corresponding author: Volodymyr Levytskyi

v.levytskyi@ztu.edu.ua ing stone. Brand new means of care and improvement of its qualitative indicators are appearing. According to the above mentioned, it is necessary to investigate the impact of each type of natural facing stone.

In publications (Korobiichuk, I. et al., 2015; Korobiichuk, V. et al., 2016; Korobiichuk, I. et al., 2016) the influence of chemical and mechanical natural facing stone working on its lightness and lustre on the example of Pokostivskyi granodiorite was studied. Also, these studies resolved the issue of control of natural stone lightness, since in the facing of buildings with natural stone, there may be differences in the color tone of tiles, which is caused by mineralogical and chemical composition of the stone. This problem is solved both in the processing of stone by the use of different methods of chemical and mechanical working and during its output (through division of deposit sites according to structural indicators) since it is not possible to classify unworked Pokostivsky granodiorite visually by the lightness (Korobiichuk, V. et al., 2016; Levytskyi, Sobolevskyi, 2014; Levytskyi, 2017). Furthermore, lightness and lustre are influenced by environmental factors that were considered in the work (Korobiichuk, I. et al., 2016).

Mechanical methods of natural stone working are sufficiently investigated. So, with the help of microscopy and spectral analysis in works (Dawei et al., 2014; Hideo et al., 2014) the formation of micro-structure of rock-forming minerals is studied. Depending on the microhardness of granitoid rocks, the processes of abrasive working have been experimentally investigated (Xie, Tamaki, 2007). Depending on the roughness of the 
stone surface, a change of the lustre of its surface was studied (Yavuz, Ozkahraman, Demirdag, 2011).

With regard to research related to chemical processing, we have investigated the influence of different colour pigments on the lustre and colour indicators of carbonate rocks (marble, limestone) (Khedkar et al., 2017; Carmona-Quiroga et al., 2010; Malaga-Starzec et al., 2006). In addition, the publication (Malaga-Starzec et al., 2006) studied the effect of impregnating means into the porosity of marble as well as the depth of impregnation (Cnudde et al., 2007).

Analysis of the literature shows that most studies are related to mechanical processing. Also, most experiments have been carried out on shallow carbonate rocks containing a single rock-forming mineral. Therefore, it is necessary to explore the effectiveness of chemical treatment for high-strength rocks.

\section{Material and methods}

\subsection{Materials and equipment}

During the study, 35 samples of the following types of natural facing stone ( 7 types of stone with 5 samples to each type) were used: Pokostivskyi granodiorite (Grey Ukraine), Bukivskyi gabbro (Galant), Golovinskyi labradorite (Black Sea), Mezhyritskyi granite (Rosso Pink), Kapustynskyi granite (Rosso Santiago), Zhadkivskyi granite (Rosa Raveno), Leznykivskyi Granit (Ukrainian Red). The mineralogical composition of the used types of natural facing stone is given in Table $\mathbf{1}$.

As a diamond tool, tillers with numbers and graininess were used as shown in Table 2.

Also the numbers show the quantity of passes. Such a scheme of using the diamond tool obtains a high-quality surface of the stone and provides it with the ultimate lustre.

For this purpose, special impregnating products were put on the polished surfaces of equally processed samples of the stone.

The following impregnation chemicals were used in the experiments:

1. Impregnation agent $1(\mathrm{pH}=5.36)$ is a varnish based impregnation agent, which gives the surface the effect of wet stone and is used for surface treatment of all types of natural stone to protect it from moisture, oil, grease, and to enhance the colour;

Table 1. The mineralogical composition of the used types of natural facing stone

\begin{tabular}{|l|c|c|c|c|c|c|}
\hline \multirow{2}{*}{ Stone type } & \multicolumn{5}{|c|}{ The content of the mineral, \% } \\
\cline { 2 - 7 } & Microclin & Plagioclase & Quartz & Biotite & Pyroxene & Other \\
\hline $\begin{array}{l}\text { Pokostivskyi granodiorite } \\
\text { (Grey Ukraine) }\end{array}$ & $15-30$ & $35-55$ & $10-25$ & $5-15$ & - & 1 \\
\hline Bukivskyi gabbro (Galant) & $2-9$ & $57-72$ & 5 & 3 & $25-32$ & $0-14$ \\
\hline $\begin{array}{l}\text { Golovynskyi labradorite } \\
\text { (Black Sea) }\end{array}$ & 3 & 85 & 7 & 1 & - & 1 \\
\hline $\begin{array}{l}\text { Mezhyritskyi granite } \\
\text { (Rosso Pink) }\end{array}$ & 60 & 20 & 15 & 5 & - & 1 \\
\hline $\begin{array}{l}\text { Kapustynskyi granite } \\
\text { (Rosso Santiago) }\end{array}$ & 50 & 24 & 18 & 7 & - & - \\
\hline $\begin{array}{l}\text { Zhadkivskyi granite } \\
\text { (Rosa Raveno) }\end{array}$ & 60 & 20 & 15 & 5 & - & - \\
\hline $\begin{array}{l}\text { Leznykivskyi granite } \\
\text { (Ukrainian Red) }\end{array}$ & 80 & - & 15 & 5 & - & - \\
\hline
\end{tabular}

Table 2. The characteristics of the used diamond tool

\begin{tabular}{|l|l|c|}
\hline $\begin{array}{l}\text { Quantity } \\
\text { of passes }\end{array}$ & Tool numbers & $\begin{array}{c}\text { Graininess, } \\
\boldsymbol{\mu m}\end{array}$ \\
\hline & №.00 (diamond) & $710 / 600$ \\
\hline $\mathbf{1}$ & № 24 & $500 / 400$ \\
\hline $\mathbf{1}$ & № 240 & $200 / 160$ \\
\hline $\mathbf{4}$ & № 400 & $80 / 63$ \\
\hline $\mathbf{2}$ & № 600 & $60 / 40$ \\
\hline $\mathbf{2}$ & № 800 & $40 / 28$ \\
\hline $\mathbf{2}$ & № 1200 & $28 / 20$ \\
\hline $\mathbf{2}$ & № 1500 & $20 / 14$ \\
\hline $\mathbf{2}$ & № 2000 & $10 / 7$ \\
\hline $\mathbf{2}$ & № 3000 & $5 / 3$ \\
\hline $\mathbf{1}$ & Polishing & $1 / 0$ \\
\hline
\end{tabular}

2. Impregnation agent $2(\mathrm{pH}=3.98)$ is a transparent crystallizer, based on the solution of silicate with wax, which is used to improve lustre and colour saturation of all types of natural facing stone;

3. Impregnation agent $3(\mathrm{pH}=9.12)$ is a black crystallizer for products of natural stone (black shades) such as granite, gabbro, and labradorite. The product deeply penetrates and closes the pores, microcracks, protecting the stone from damage. It enhances and enriches the colour of the stone and gives the stone a delicate lustre;

4. Impregnation agent $4(\mathrm{pH}=7.45)$ is a red crystallizer, on the basis of the solution of silicates with red pigments for products from a natural stone (red shades). It is used to saturate colours, to emphasize texture and increase the lustre of the stone. 


\subsection{Evaluation of the effectiveness of natural facing stone surface treatment by mechanical and chemical methods}

Methods of evaluating the effectiveness of natural facing stone surface treatment by mechanical and chemical methods lies in using digital images of specimens and performing processing by modern computing means.

The method of determining natural facing stone colour characteristics is as follows:

- natural facing stone samples with dimensions of $10 \times 20 \mathrm{~cm}$ are selected;

- scanning of the stone samples surfaces carried out using the scanner Skypix TSN 415 is performed;

- the obtained image is processed in the Mdistones program; the average lightness indicators $(L)$ and the color coordinate $A$ and $B$ in a LAB color system of investigated sample surfaces are determined (see Figure 1);

- parameters of S saturation obtained are defined by converting the average color coordinates in the LAB system in the HSV colour model.

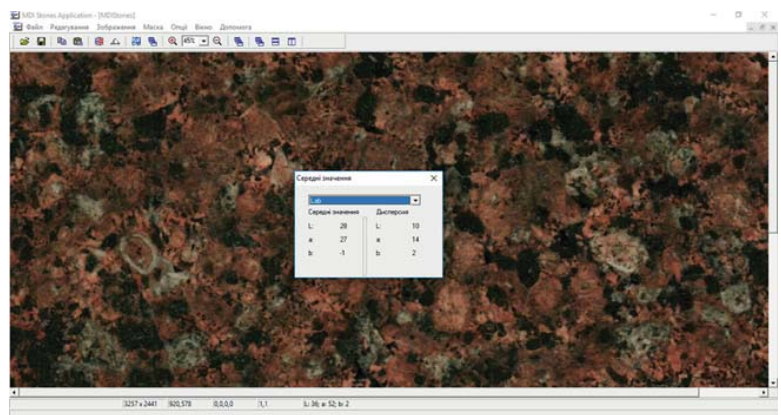

Figure 1: Image sample processing of Mezhyritsky granite in the Mdistones program

The surface lustre of natural facing stone is measured by a glossmeter.

Methods of determination of the natural facing stone surface lustre are performed according to this principle:

1. Cleaning samples from dust, dirt and other substances that can contaminate the surface is carried out.

2. Calibration of the device with the benchmark.

3. Measurement of lustre at 6 different points on the sample is performed.

4. Average lustre values of the natural facing stone surface for each of the samples are determined.

\section{Results and discussion}

To assess the effectiveness of surface treatment of natural facing stone by mechanical and chemical methods, it is essential to firstly determine the average lustre of the surface. According to the lustre measurement re-

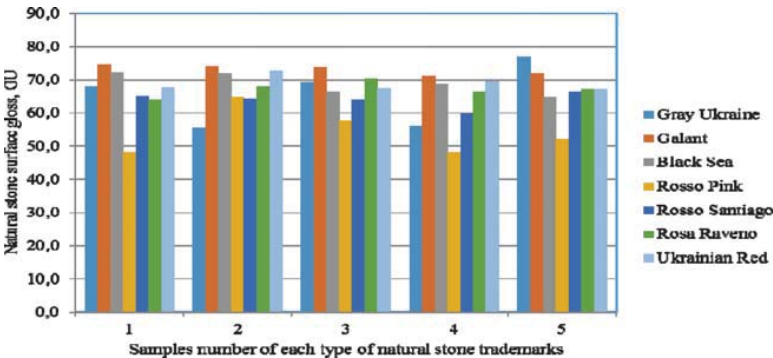

Figure 2: The average lustre values of machined natural stone samples with a polished texture

sults, a chart of the average lustre values of worked natural stone samples of different types with a polished texture was constructed (see Figure 2).

After determining the lustre of the polished rock samples, the impregnation of chemicals between the impregnation process and the process of taking the readings is performed; the necessary period of time for deep absorption by the sample surface and the best saturation is indispensable, otherwise the lustre value will be false. A change in the lustre after treatment by mechanical and chemical methods is shown in Figure 3.

The diagram of average lustre values changes after chemical impregnating means processing for the polished surface of natural stone shows that while the chemical treatment lustre increases due to different natural stone types: in the processing by means of Impregnation agent 1 - from 0.3 to $12.7 \mathrm{GU}$, the processing by means of Impregnation agent 2 - from 0 to $3.8 \mathrm{GU}$, the processing by means of Impregnation agent 3 - from 0.5 to $9.2 \mathrm{GU}$, the processing by means of Impregnation agent 4 - from 0.7 to $7.5 \mathrm{GU}$,

An important component in determining the decorative natural facing stone is an objective determination of colour characteristics.

Colour is characterized by the following main features: hue, saturation and lightness.

All colours perceived by a man are divided into chromatic (I) and achromatic (II). Chromatic colors include yellow, red, blue, and composite colours resulting from the merger of two or three primary colours, e.g. orange, purple, green.

Achromatic colours are black, grey, dark grey, medium grey, light grey, white grey and white colours, different from each other by the level of lightness. Determination of colour characteristics is performed organoleptically, with the following characteristics indicated in the Table 3.

As can be seen from Table 3, the greater the saturation, the greater decorativeness of natural stone. Also, the weaker the lightness of the stone, the higher its decorative effect.

Lightness measurement and the saturation of natural facing stone surfaces processed by mechanical methods using digital image processing was conducted. According to the results of lightness and saturation measure- 


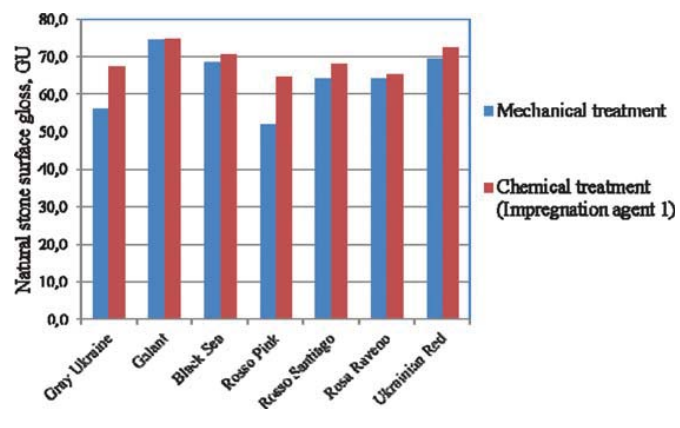

$a$

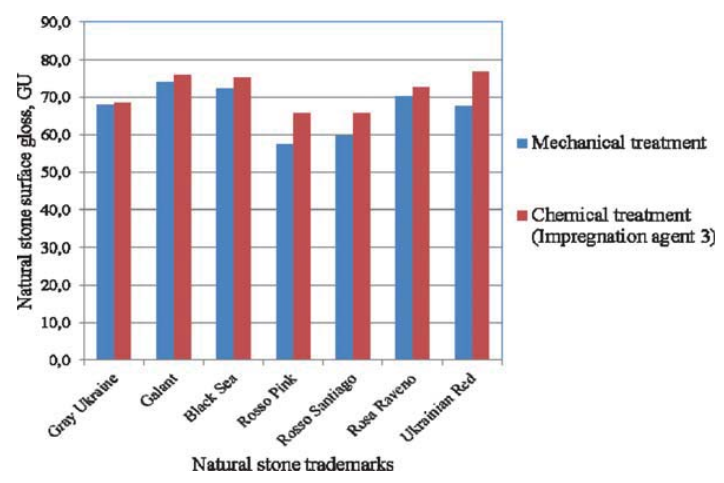

$c$

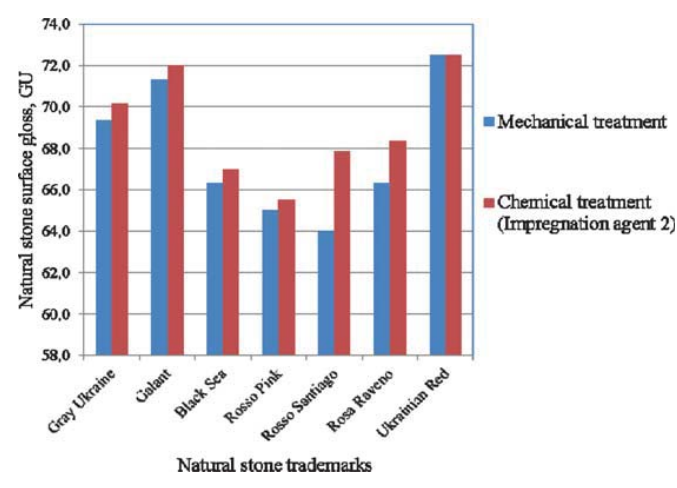

$b$

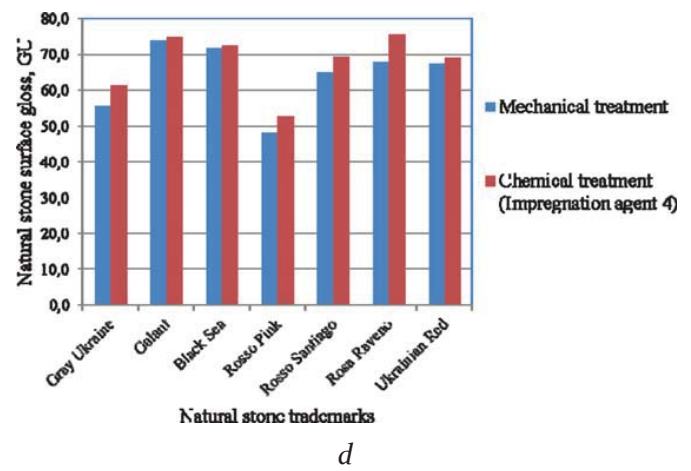

Figure 3: Charts of changes in average values of gloss after treatment by chemical impregnating means of polished stone textures: $a$ - Impregnation agent 1, $b$ - Impregnation agent 2, $c$ - Impregnation agent 3, $d$ - Impregnation agent 4

Table 3. Determination of basic features of colour

\begin{tabular}{|c|c|c|c|c|}
\hline $\begin{array}{l}\text { The main decorative } \\
\text { indicator }\end{array}$ & $\begin{array}{l}\text { Decorative } \\
\text { feature (positive) }\end{array}$ & $\begin{array}{l}\text { Feature } \\
\text { category }\end{array}$ & $\begin{array}{l}\text { Feature } \\
\text { characteristic }\end{array}$ & $\begin{array}{l}\text { Evaluation, } \\
\text { points }\end{array}$ \\
\hline \multirow[t]{9}{*}{ Colour } & \multirow[t]{2}{*}{ Colouration } & I & Chromatic & 5 \\
\hline & & II & Achromatic & 2 \\
\hline & \multirow[t]{4}{*}{ Saturation } & $\mathrm{I}$ & $\begin{array}{l}\text { Intensely saturated } \\
(0,8-1,0)\end{array}$ & 6 \\
\hline & & II & $\begin{array}{l}\text { Medium saturated } \\
(0,4-0,8)\end{array}$ & 4 \\
\hline & & III & $\begin{array}{l}\text { Weakly saturated } \\
(0,1-0,4)\end{array}$ & 3 \\
\hline & & IV & Unsaturated $(0,1)$ & 1 \\
\hline & \multirow[t]{3}{*}{ Lightness } & I & $\begin{array}{l}\text { Black, white grey, } \\
\text { white }\end{array}$ & 4 \\
\hline & & II & $\begin{array}{l}\text { Light grey, medium } \\
\text { grey }\end{array}$ & 2 \\
\hline & & III & Dark grey, black grey & 1 \\
\hline
\end{tabular}

ment, a chart of their average values while mechanical treatment of natural stone samples with a polished texture was constructed (see Figure 4).

Also, the effect of chemical treatment on the lightness (see Figure 5) and saturation (see Figure 6) of the natural facing stone surface was investigated.

The diagram of the average lightness values changes after processing with the chemical impregnating of natural stone with polished surface shows that while the chemical treatment lightness increases due to different types of natural stone: in the processing by means of Impregnation agent 1 - from 1 to $10 \%$, the processing by means of Impregnation agent 2 - from 1 to $9 \%$, the processing by means of Impregnation agent 3 - from 2 to $14 \%$, the processing by means of Impregnation agent 4 - from 0 to $12 \%$.

The diagram of the average saturation values after processing with the chemical impregnating means of 


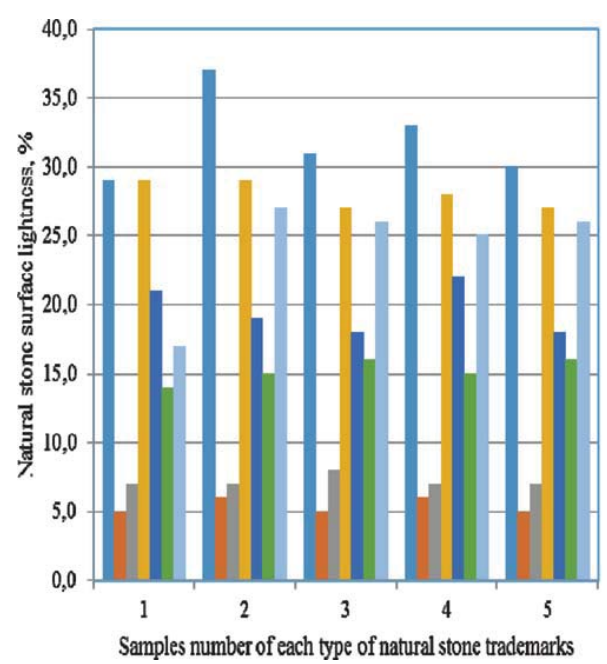

$a$

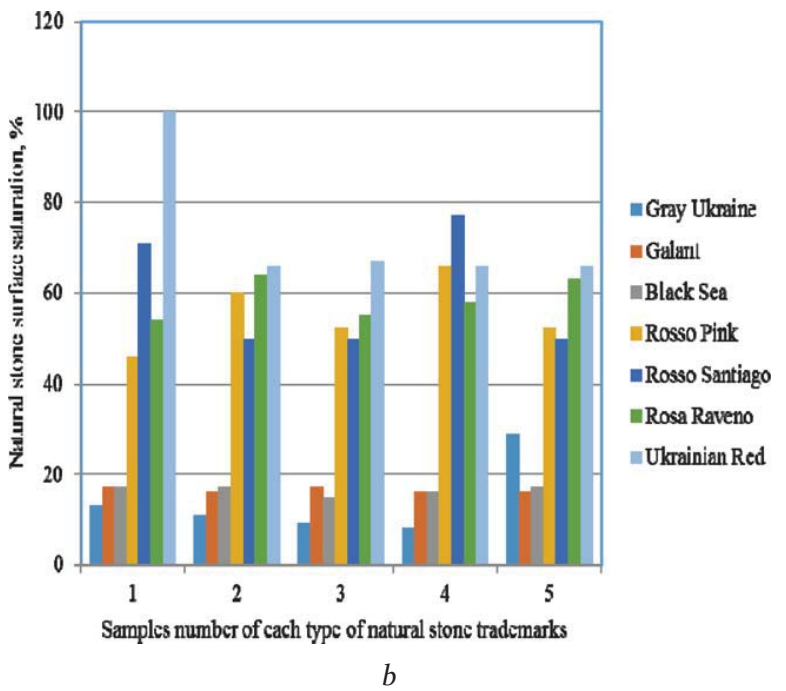

$b$

Figure 4: The average lightness $(a)$ and saturation $(b)$ values of machined natural stone samples with a polished texture

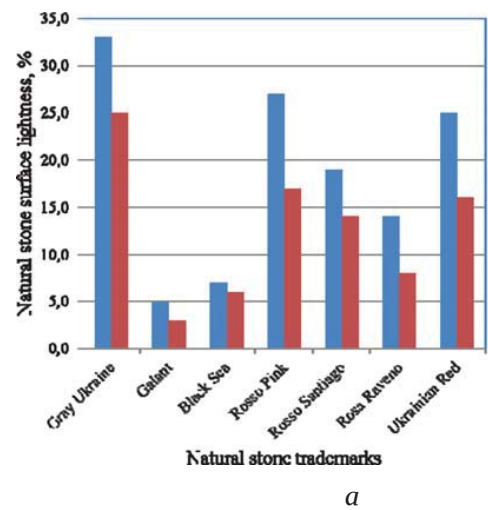

Mechanical treatment

- Cihomical trcatment

(Impregnation agent 1)
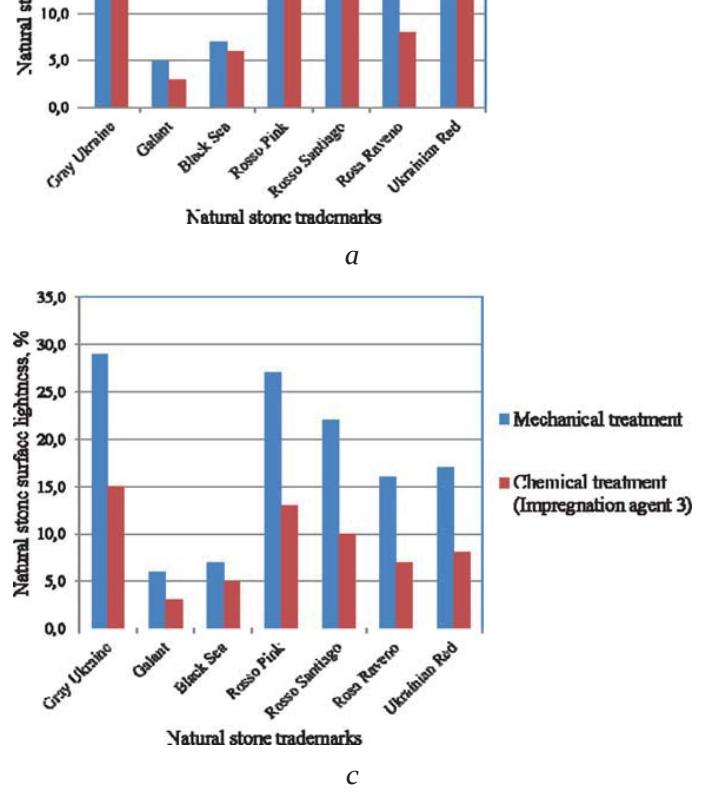

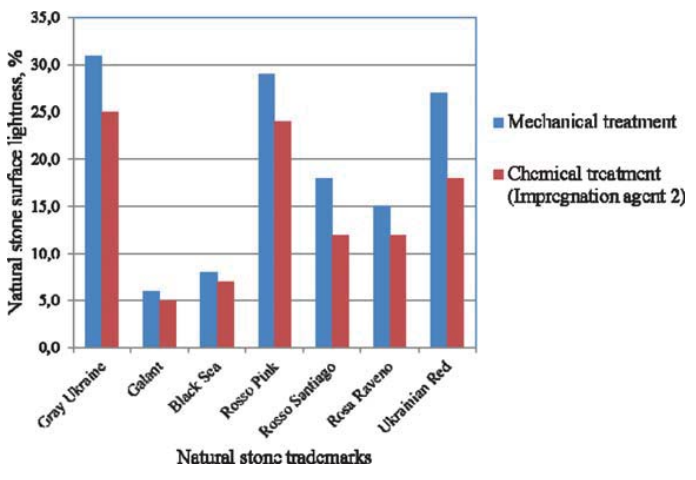

$b$

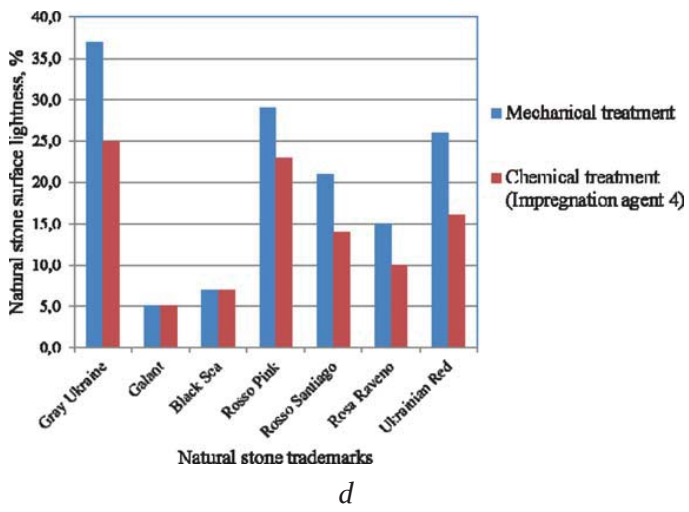

Figure 5: The average lightness values after treatment with chemical impregnating means (polished texture): $a$ - Impregnation agent 1, $b$ - Impregnation agent 2, $c$ - Impregnation agent 3, $d$ - Impregnation agent 4

natural stone with polished surface shows that while the chemical treatment saturation increases due to different types of natural stone: in the processing by means of Impregnation agent 1 - from 4 to $32 \%$, the processing by means of Impregnation agent 2 - from -16 to $48 \%$, the processing by means of Impregnation agent 3 - from -83 to $3 \%$, the processing by means of Impregnation agent 4 - from -1 to $48 \%$.
After the operations associated with the definition of lightness and saturation on the processed polished surface by mechanical and chemical methods, we turn to the definition of these indicators with a dusty surface, which is similar to previous studies. Conducting the study, we obtained the following data: dusty samples have a greater lightness than polished samples during mechanical processing and saturation and lightness of 


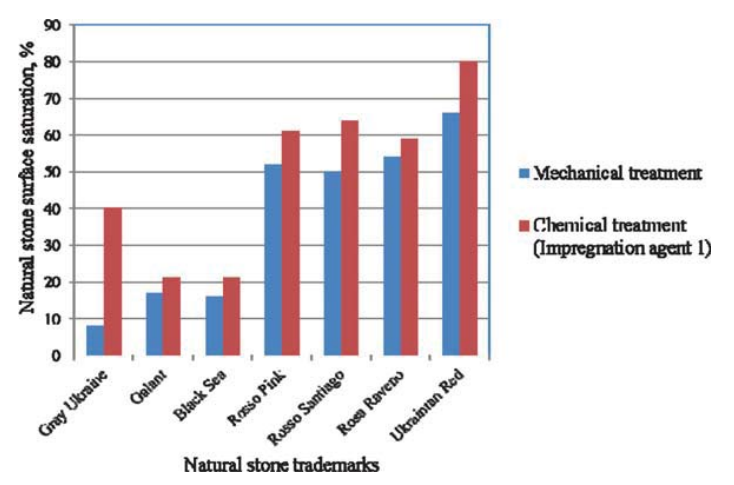

$a$
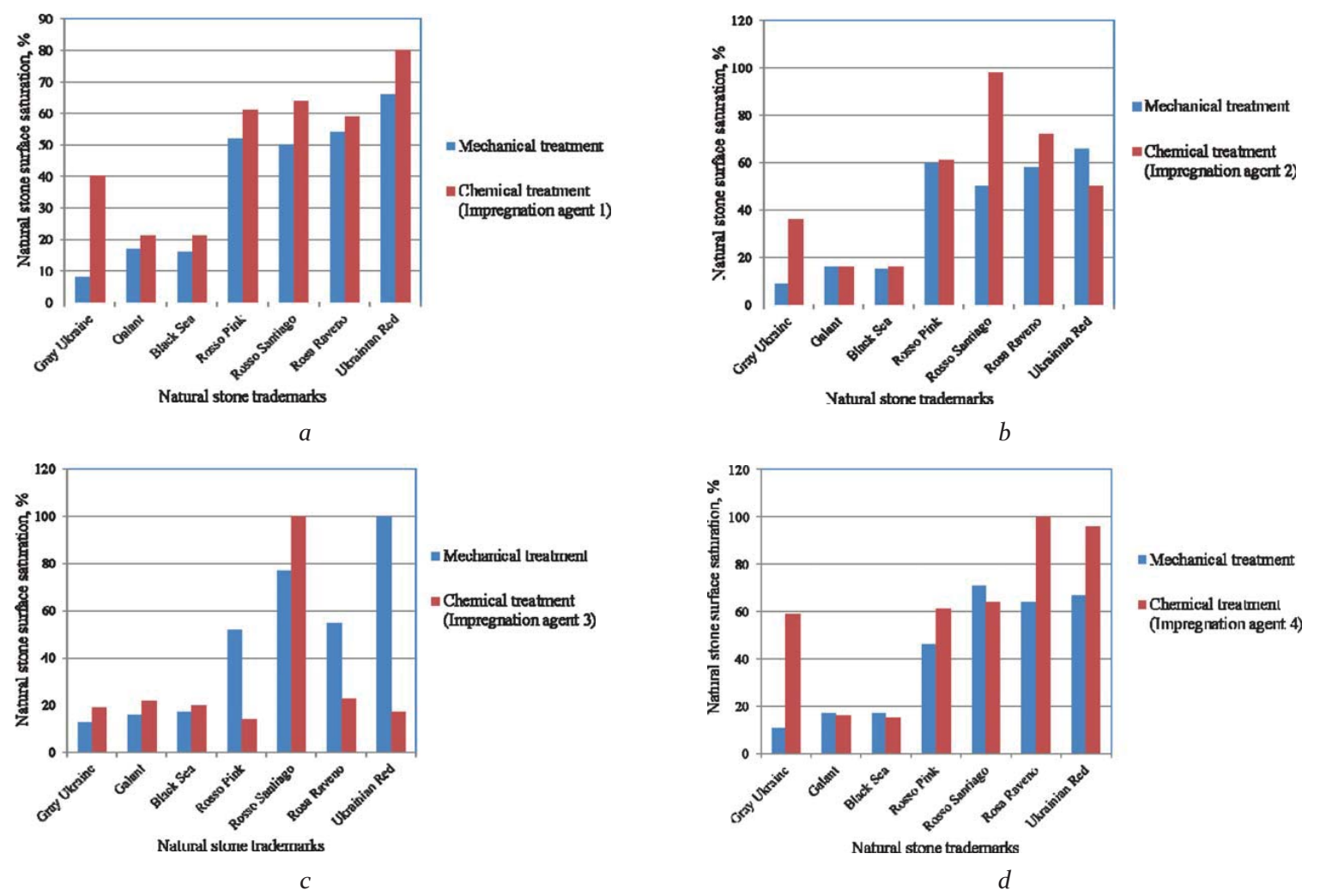

Figure 6: The average saturation values after treatment with chemical impregnating means (polished texture): $a$ - Impregnation agent 1, $b$ - Impregnation agent 2, $c$ - Impregnation agent 3, $d$ - Impregnation agent 4

the treated surface of natural facing stone vary considerably during chemical treatment.

Natural facing stone is characterized by its diversity and uneven colouring. The reason for this is different mineralogical and chemical composition of natural stone. When installing tiles of natural stone of different colour tone, there is a difference in the perception by the visual analyzer of the person. The authors in previous publications (Korobiichuk, I. et al., 2015; Korobiichuk, V. et al., 2016) proved that lightness of the surface of the natural stone can be managed by the various mechanical and chemical methods. Since there is a great number of agents for chemical treatment, the authors investigated the impact of these agents on lustre, lightness and saturation of various types of natural facing stone depending on mineralogical composition.

As a result of the research, it can be concluded that each of the chemical impregnating agents affects the decorative characteristics of the surface of the natural facing stone in different ways. They increase lustre, darken the stone, and can improve its saturation as well as worsen it. We have also found the confirmation of this in the examined materials (Khedkar et al., 2017; Carmona-Quiroga et al., 2010; Malaga-Starzec et al., 2006), in which the influence of marble chemical treatment on lustre and colour characteristics was investigated. Depending on the type of the applied means, the saturation of the stone has both increased and decreased
(Malaga-Starzec et al., 2006). Their efficiency depends on the mineralogical composition of natural stone. So, Impregnation agent 1 and Impregnation agent 2 interact with plagioclase and microcline but they interact poorly with quartz, Impregnation agent 3 interacts with the plagioclase, but it interacts poorly with microcline and quartz; Impregnation agent 4 interacts with microcline but it interacts poorly with plagioclase and quartz.

In the future, it is planned to investigate the surface decorative indicators changes of natural stone, which is processed by chemical and mechanical methods after exposure to ultraviolet radiation and high temperatures. It is also planned to investigate the physical and mechanical property changes of natural stone, such as water absorption and frost resistance, depending on the type of natural stone chemical and mechanical treatment.

\section{Conclusions}

As a result of the study the following peculiarities were revealed:

1. The indicators of lustre of natural facing stone surfaces worked by mechanical and chemical methods are identified. When the chemical treatment on different types of natural stone lustre increases: in the processing by means of Impregnation agent 1 - from 0.3 to $12.7 \mathrm{GU}$, in the processing by means of Impregnation agent 2 from 0 to $3.8 \mathrm{GU}$, in the processing by means of Impreg- 
nation agent 3 - from 0.5 to $9.2 \mathrm{GU}$, in the processing by means of Impregnation agent 4 - from 0.7 to $7.5 \mathrm{GU}$.

2. The indicators of lightness of natural facing stone surfaces worked by mechanical and chemical methods are identified. When the chemical treatment on different types of natural stone lightness decreased: in the processing by means of Impregnation agent 1 - from 1 to 10 $\%$, in the processing by means of Impregnation agent 2 - from 1 to $9 \%$, in the processing by means of Impregnation agent 3 - from 2 to $14 \%$, in the processing by means of Impregnation agent 4 - from 0 to $12 \%$.

3. The indicators of saturation of natural facing stone surfaces worked by mechanical and chemical methods are identified. When the chemical treatment on different types of natural stone saturation varies: in the processing by means of Impregnation agent 1 - from -7 to $39 \%$, in the processing by means of Impregnation agent $2-$ from 1 to $18 \%$, in the processing by means of Impregnation agent 3 - from -21 to $91 \%$, in the processing by means of Impregnation agent 4 - from 6 to $17 \%$.

\section{References}

Carmona-Quiroga, P. M., Martínez-Ramírez, S., de Rojas, M. S., \& Blanco-Varela, M. T. (2010). Surface water repellent-mediated change in lime mortar colour and gloss. Construction and Building Materials, 24 (11), 2188-2193.

Cnudde, V., Dierick, M., Vlassenbroeck, J., Masschaele, B., Lehmann, E., Jacobs, P. \& Van Hoorebeke, L. (2007). Determination of the impregnation depth of siloxanes and ethylsilicates in porous material by neutron radiography. Journal of Cultural Heritage, 8 (4), 331-338.

Dawei, W., Xianhua, C., Markus, O., Helge, S. \& Bernhard, S. (2014). Study of micro-texture and skid resistance change of granite slabs during the polishing with the Aachen Polishing. Wear, 318 (1-2), 1-11.

Hideo, A., Hidetoshi, T., Seong-Woo, K., Natsuko, A., Koji, K., Tsutomu Y. \& Toshiro, D. (2014). Evaluation of subsurface damage in GaN substrate induced by mechanical polishing with diamond abrasives Applied Surface Science, 292, 531-536.

Khedkar, S. V., Thorat, P. V., Pande, P. S., \& Gopalani, R. P. (2017). Study of Separation of Pigments in Paints for Development of Multicolor Paint. Journal for Research, 3 (04).

Korobiichuk, I., Korobiychuk, V., Nowicki, M., Shamrai, V., Skyba, G. \& Szewczyk R. (2016). The study of corrosion resistance of Pokostivskiy granodiorites after processing by various chemical and mechanical methods. Construction \& Building Materials, 114, 241-247.

Korobiichuk, I., Shamrai, V., Korobiychuk, V., Nowicki, M. \& Szewczyk, R. (2015). The study of the influence of natural stone surfaces polishing by different methods on the hues of lightness. In 11th International Conference «Mechatronic systems and materials», 105-106.

Korobiichuk, V., Shamrai, V., Iziumova, O., Tolkach, O. \& Sobolevskyi, R. (2016). Definition of hue of different types of pokostivskiy granodiorite using digital image processing. Eastern-European Journal of Enterprise Technologies, 4 (5), 52-57.

Levytskyi, V. (2017). The new approach of using image and range based methods for quality control of dimension stone. Reports on Geodesy and Geoinformatics, 103, 6677. DOI: https://doi.org/10.1515/rgg-2017-0006.

Levytskyi, V., Sobolevskyi R. (2014). Decorative stone block quality control based on surface digital photogrammetry. Scientific Bulletin of National Mining, 6, 58-66.

Malaga-Starzec, K., Åkesson, U., Lindqvist, J. E., \& Schouenborg, B. (2006). Microscopic and macroscopic characterization of the porosity of marble as a function of temperature and impregnation. Construction and Building Materials, 20 (10), 939-947.

Xie, J. \& Tamaki, J. (2007). Parameterization of Micro-Hardness Distribution in Granite Related to Abrasive Machining Performance. Journal of Materials Processing Technology, 186 (1-3), 253-258.

Yavuz, H., Ozkahraman, T. \& Demirdag S. (2011). Polishing experiments on surface quality of building stone tiles. Construction and Building Materials, 25 (4), 1707-1711. 